\title{
IS HEALTH CONSCIOUSNESS IMPORTANT AT THE TIME OF CORONAVIRUS? THE CASE OF SLOVAKIA AND HUNGARY
}

\section{Čvirik, M.}

Marián Čvirik / University of Economics in Bratislava, Faculty of Commerce, Department of Marketing, Dolnozemská cesta 1, 85235 Bratislava, Slovakia.Email: marian.cvirik@euba.sk.

\begin{abstract}
The whole world is trying to keep the coronavirus under control. However, it is certain that the consequences of coronavirus do not affect the world economy but also health care and health-conscious consumer behaviour. The first wave of coronavirus came under control when the second wave appeared. What impact will this wave have on consumers' health consciousness? The article focuses on examining the difference between the level of health consciousness at the time of the decline of the first wave and the release of measures against coronavirus and the second upcoming wave of the mutated version of the virus. The main goal of the state is to examine the level of health consciousness and follow the recommendations of W.H.O. against the spread of coronavirus in Slovakia and Hungary during the decline and re-emergence of coronavirus. The research consisted of two phases - the first phase after the first wave of the pandemic and the second during the onset of the second phase. The one-way ANOVA test and linear regression analysis were used to explore the relationship between health consciousness and W.H.O's recommendations in the fight against coronavirus. The results indicate a close connection in the conditions of Slovakia and Hungary. At the same time, we concluded that health consciousness changes due to the acuteness of the situation. The results can be used in many fields (medicine, sociology, psychology, marketing), both theories and practice.

Implications for Central European audience: European countries, as well as the whole world, are fighting the coronavirus. Preliminary results suggest that the second wave will bring more infected. Health consciousness and prevention provide the best opportunity to fight coronavirus in times without an effective vaccine. It is, therefore, the role of the responsible authorities to examine the level of health consciousness and to try to influence it positively. The results suggest that only proper consumer information and adherence to the basic recommendations of W.H.O. can positively affect the level of health consciousness.
\end{abstract}

Keywords: health consciousness; consumer health behaviour; COVID-19.

J.E.L. Classification: M30, I11, I19

\section{Introduction}

Only a few authors address the topic of health consciousness, but it is at the time of the pandemic that this topic has an important place. The first wave of the virus will be tackled by 
European countries, but more than 800,000 people have died worldwide, and more than 6 million people are still actively infected, threatening others. In times without a vaccine, the only solution is prevention, which stems from health consciousness.

Due to the management of the first wave, measures were taken to combat coronavirus. Many people go abroad, increasing their chances of getting ill. Due to Schengen, it is possible to travel practically all over Europe. The second wave comes during the summer, with manifestations mainly in August.

What is the level of health consciousness of consumers in the release phase? Will this value increase during the second wave of coronavirus? What role do the recommendations of the World Health Organization play? Does the willingness to follow these recommendations affect the level of health consciousness? What effect does the interest in information on coronavirus have on health consciousness? Is the informed consumer vigilant? We are looking for answers to these and other questions in the presented article.

\section{Theoretical background}

\subsection{Health and Health consciousness}

The most used and most accepted definition of health is from World Health Organization (abbrev W.H.O.) defined health as "a state of complete physical, mental and social well-being and not merely the absence of disease or infirmity" (W.H.O., 2020a). We consider the biggest limit of the definition to be that it does not identify indicators or parameters of health quality (measurable), for which it is necessary to state, for example, human life, specific conditions, gender, age, and thus human life cycle. Stokes et al. (1982, p. 34) defined health as "a state characterized by anatomic, physiologic and psychological integrity; ability to perform personally valued family, work and community roles, ability to deal with physical, biological, psychological and social stress". Health 2020 is the new European health policy framework, which aims to support action across government and society to: "significantly improve the health and well-being of populations, reduce health inequalities, strengthen public health and ensure people-centred health systems that are universal, equitable, sustainable and of high quality" (W.H.O., 2020b). It is also possible to approach this goal thanks to the health consciousness of consumers.

Health consciousness refers to the extent to which an individual tends to undertake health actions (Gould, 1988). Gould (1990) defines health consciousness as the inner status of a person regarding health. Health consciousness can understand as the motivation that stimulates consumers to take health activities and prevent them (Jayanti \& Burns, 1998; Michaelidou \& Hassan, 2008). Čvirik (2020, p. 47) defines consumers with a high level of health consciousness as consumers who "seek to improve and/or maintain their welfare by engaging in healthy behaviours, as eating healthy food, physical activity, caring for prevention, and the like". Previous research has revealed health consciousness supports preventive health care (Jayanti \& Burns, 1998) and consumer shopping behaviour (Lockie et al., 2002).

Čvirik (2020) proved that health consciousness has a significant impact on the fight against the COVID-19 pandemic. The study showed that during the pandemic, the level of health consciousness in Slovakia increased and also that it has a significant impact on the spread of the pandemic. 


\subsection{Brief characteristics of coronavirus and its influence in the conditions of Slovakia and Hungary}

The term coronavirus appears in the conditions of Slovakia and Hungary around the beginning of 2020. Due to the number of infected, a pandemic situation is emerging, which has a negative effect on the whole world. Coronavirus can cause clinical diseases in humans that may extend from the common cold to more severe respiratory diseases like SARS (Lu et al., 2020).

As stated European Centre for Disease Prevention and Control (ECDC, 2020): "The COVID-19 pandemic is rapidly evolving, and outbreak investigations are ongoing. ECDC is closely monitoring this outbreak, providing risk assessments, public health guidance, and advice on response activities to the E.U. Member States and the E.U. Commission." Coronavirus infection in humans is commonly associated with low to severe respiratory diseases that are characterized by fever, severe inflammation, cough, and internal organs dysfunction that can even lead to death. (Kritas et al., 2020)

The first case was recorded in Slovakia on March 7, 2020, while in neighbouring Hungary, the first case was recorded three days earlier. Both countries have issued various measures to reduce the spread of coronavirus since the outbreak. However, after the measures have been relaxed, according to current data, the number of infected people is starting to rise again. It is necessary to consider not only the number of infected but also the number of cured, and therefore in work, we will consider mainly the number of active cases. The current situation of Slovakia and Hungary is documented in Graph 1 and Graph 2.

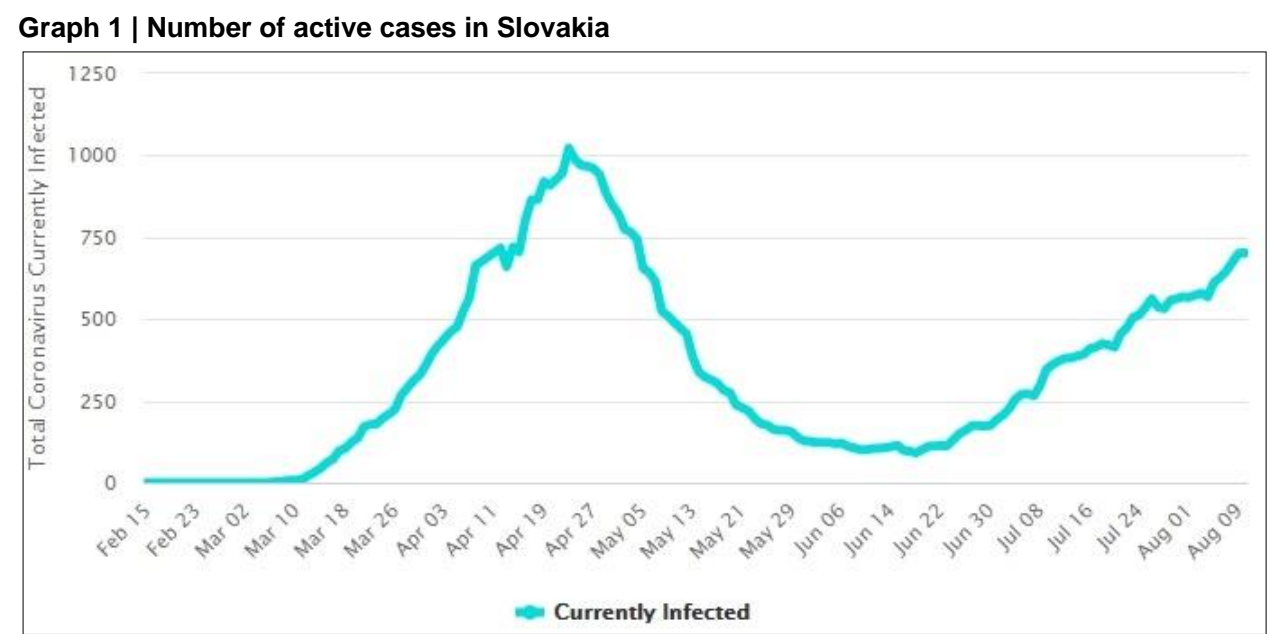

Source: Adapted from Worldometers, 2020a. 


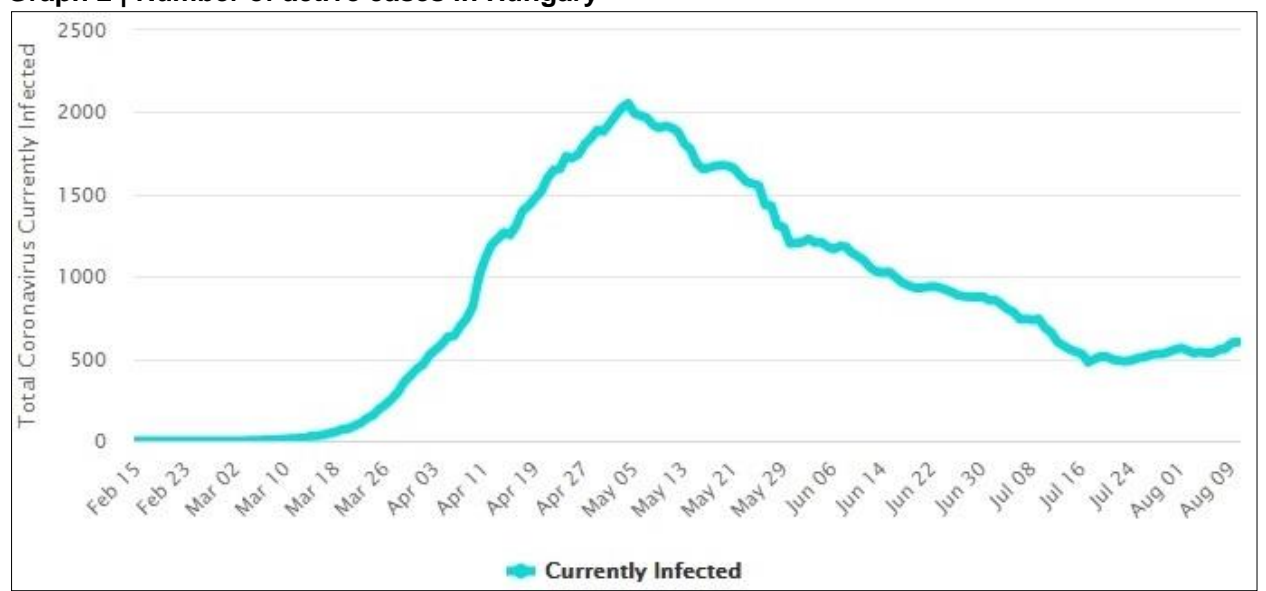

Source: Adapted from Worldometers, 2020b.

As Chart 1 shows, the number of active cases in Slovakia is growing again. Graph 2 graphically shows the chronological development of active cases in Hungary. As we can see, the number has increased slightly, but not as dramatically as in Slovakia. Currently, as of August 10, 2020, Slovakia has 702 active cases and Hungary 601 cases. It can be stated that Hungary is managing its fight against coronavirus better so far. Given the population (Slovakia - 5,459,642; Hungary - 9,660,351, Worldometer, 2020c) and the area of both countries (Slovakia 49,035 $\mathrm{km}^{2}$, Hungary - 93,030 $\mathrm{km}^{2}$ ), it would be logical for Hungary to have a higher number of active cases. However, but is it not. Of course, several factors need to be taken into accounts, such as the measures in place in the country, the population density, the health status of the population and many other factors. We also consider the behaviour of the population to be an important factor, which we pay more attention to at work in the form of health consciousness.

\section{Methodology}

The main goal of the state is to examine health consciousness and follow the recommendations of W.H.O. against the spread of coronavirus in Slovakia and Hungary during the decline and re-emergence of coronavirus.

For the scope of the main goal, we divided it into four partial goals:

1. Measurement of the level of health consciousness during the remission of a pandemic (coronavirus) in Slovakia and Hungary,

2. Measurement of the level of health consciousness during the onset of the second wave of coronavirus,

3. Examination of differences between health consciousness during decline and reemergence of coronavirus in Slovaks and Hungarians,

4. Examining the impact of health consciousness on compliance with and implementation of W.H.O. preventive recommendations against the spread of coronavirus. 


\subsection{Sample}

A pandemic threatens each demographic group differently. Seniors over 65 are considered the most vulnerable group (Adler, 2020). Less than one per cent of the cases were reported in kids younger than ten years of age. (Wu \& McGoogan, 2020) This is one of the reasons why we have also looked at demographic factors - age. Based on laboratory tests at New York City Health, the following coronavirus mortality can be found based on age: 0 - 17 years $0.06 \%, 18$ - 44 years $3.9 \%, 45-64$ years $22.4 \%, 65-74$ years $24.9 \%$ and 75 and over $48.7 \%$. (N.Y.C. Health, 2020) Based on the above, a strong influence of patients' age on mortality can be stated, while it can be stated that with increasing age, the probability of death from coronavirus also increases. We have therefore chosen a quota sample to maintain this demographic variable from the basic population.

The first stage was to determine quotas in basic population in Slovakia and in Hungary (see Table 1). The second stage was to apply quotas to create the sample what can be seen in Table 1. The basic basis for our research consisted of 384 Slovaks and 384 Hungarians (the total research sample represents 768 respondents).

Table 1 I Quotas and their application (Quotas sample)

\begin{tabular}{c|ccc}
\hline Factor - age & & Quotas [\%] & Quotas applied [pcs.] \\
\hline \multirow{3}{*}{ Slovakia* $^{*}$} & $15-39$ years old & 40.3 & 155 \\
& 40-64 years old & 41.3 & 159 \\
& Older than 65 years & 18.4 & 70 \\
\hline \multirow{3}{*}{ Hungary $^{\star *}$} & $15-39$ years old & 35.5 & 137 \\
& 40-64 years old & 41.3 & 158 \\
& Older than 65 years & 23.2 & 89 \\
\hline$\Sigma$ & & $\mathbf{1 0 0}$ & $\mathbf{3 8 4}$ \\
\hline
\end{tabular}

Source: own calculation based on *SOSR (2020) and ${ }^{* *}$ Population city (2020).

As shown in Table 1, the sample surveyed represents a representative sample of the population of Slovakia (Hungarian) older than 15 years according to the age quota. For a sample of 384 respondents, the maximum statistical error (with a $95 \%$ confidence probability) is around $6 \%$.

The sample of the first and second phases is almost identical in the case of Slovakia and Hungary. In the second phase, respondents were contacted by e-mail (or by telephone or via social media) based on the contacts they provided in the questionnaire. The obtained contacts were used only for the needs of the second phase with the promise that they will not be published or further distributed. The agreement in the Slovak sample (comparison of the sample from the first phase and the sample from the second phase) was $84.90 \%(n=326)$, which means that in the second phase, $15.10 \%(n=58)$ of new respondents were selected on the basis of quotas. The agreement in the Hungarian sample (comparison of the sample from the first phase and the sample from the second phase) was $94.01 \%(n=361)$, which means that in the second phase, $5.99 \%(n=23)$ of new respondents were selected on the basis of quotas.

\subsection{Consumer health consciousness}

Consumer health consciousness was measured on the basis of the Health Consciousness Scale (H.C.S.). The original H.C.S. is composed of nine items scored on a 
five-point Likert scale ranging from 0 to 4 . However, four factors relating to H.C.S. were empirically identified (overall alertness, self-consciousness, involvement self-monitoring of one's health). Item scores can be summed to form an overall H.C.S. score ranging from 0 (minimum) to 36 (maximum). The total H.C.S. score can be split at the median to form two groups: high health consciousness and low health consciousness. (Gould, 1988) We use a 5-point Likert scale, which we rated 1 - 5 points, with 1 point representing strong disagreement and 5 points representing strong agreement with the statement. In our case, the results will be in the range of 9 to 45 points. The median value of the scale we use is, therefore, 27 points. The research was carried out in two phases.

The first phase took place between 01.06.2020 to 15.06.2020. The aim of this phase was to measure consumer health consciousness during the remission of a pandemic (coronavirus) in Slovakia and Hungary. Mean scores, standard deviations and Cronbach's alphas for the items of HCS_SK1 (In Slovakia for the first phase) are presented in Table 2 and for items of HCS_HU1 (in Hungary for the first phase) are presented in Table 3.

Table 2 I HCS_SK1

\begin{tabular}{lccc}
\multicolumn{1}{c}{ HEALTH CONSCIOUSNESS SCALE: H.C.S. } & $\begin{array}{c}\text { Mean } \\
\text { scores }\end{array}$ & St. dev. & $\begin{array}{c}\text { Cronbach } \\
\text { alpha }^{\star \star}\end{array}$ \\
\hline 1. I reflect about my health a lot. & 2.54 & 1.01 & 0.694 \\
2. I'm very self-conscious about my health. & 1.88 & 0.32 & 0.707 \\
3. I'm generally attentive to my inner feelings about my health. & 1.83 & 0.37 & 0.711 \\
4. I'm constantly examining my health. & 2.51 & 0.82 & 0.675 \\
5. I'm alert to changes in my health. & 2.28 & 0.97 & 0.657 \\
6. I'm usually aware of my health. & 2.19 & 0.82 & 0.689 \\
7. I'm aware of the state of my health as I go through the day. & 2.32 & 0.90 & 0.672 \\
8. I notice how I feel physically as I go through the day. & 2.98 & 1.42 & 0.729 \\
9. I'm very involved with my health. & 2.42 & 0.93 & 0.719 \\
\hline
\end{tabular}

Source: Own calculation.

Notes: * Based on Gould (1988).

${ }^{* *}$ Overall Alpha $=0,739$

Table 3 I HCS_HU1

\begin{tabular}{lccc}
\multicolumn{1}{c}{ HEALTH CONSCIOUSNESS SCALE: H.C.S. ${ }^{*}$} & $\begin{array}{c}\text { Mean } \\
\text { scores }\end{array}$ & St. dev. & $\begin{array}{c}\text { Cronbach } \\
\text { alpha }\end{array}$ \\
\hline 1. I reflect about my health a lot. & 4.03 & 1.48 & 0.760 \\
2. I'm very self-conscious about my health. & 4.03 & 1.48 & 0.720 \\
3. I'm generally attentive to my inner feelings about my health. & 3.96 & 1.53 & 0.694 \\
4. I'm constantly examining my health. & 3.09 & 1.55 & 0.755 \\
5. I'm alert to changes in my health. & 2.86 & 1.87 & 0.699 \\
6. I'm usually aware of my health. & 3.04 & 1.60 & 0.691 \\
7. I'm aware of the state of my health as I go through the day. & 3.42 & 1.69 & 0.715 \\
8. I notice how I feel physically as I go through the day. & 3.87 & 1.68 & 0.668 \\
9. I'm very involved with my health. & 3.05 & 1.55 & 0.672 \\
\hline
\end{tabular}

Source: Own calculation.

Notes: * Based on Gould (1988).

${ }^{* *}$ Overall Alpha $=0.761$

Cronbach's alpha is used to investigate the reliability (accuracy and reliability of a research tool) within the internal consistency of the selected scale. As we can see in the case of 
Slovakia (first measurement), the total value of Cronbach's alpha value is 0.739 , which can be interpreted as an acceptable value, and in the case of Hungary (first measurement), the total value of Cronbach's alpha value is 0.761 , which can be interpreted as a high value. (Tavakol \& Dennick, 2011) From a practical point of view, it should also be stated that if the Cronbach's alpha value for the individual statements is higher than a total value, it is advisable to exclude this statement in future researches, as this will increase the overall accuracy and reliability of the research tool - in our case HCS_SK1 and HCS_HU1. In both cases, it is not necessary to exclude any statements, as this will not increase the reliability of the research tool. The standard deviation of the mean represents the dispersion of the calculated arithmetic mean across the different samples selected from one main population. The standard deviation shows to what extent the individual measured values are around the mean value. The smaller the standard deviation, the closer the measured values are to the mean value. If the variance is smaller, it can be understood that the statement was rated similarly by all respondents. In the case of Slovakia (HCS_SK1), we see a low rate of standard deviation, which can be understood as a strong consistency of responses. In the case of Hungary (HCS_HU1), we can notice a significantly higher rate of standard deviation, which can be understood as a higher diversity of respondents' answers.

The second phase took place between 20.07.2020 to 09.08.2020, when the COVID-19 pandemic broke out again in Slovakia and Hungary.

The aim of this phase was to measure the level of health consciousness at the time of increased infection with coronavirus. In the conditions of Slovakia, we can talk about the second wave, but in the case of Hungary, this cannot be clearly stated.

Mean scores, standard deviations and Cronbach's alphas for the items of HCS_SK2 (In Slovakia for the second phase) are presented in Table 4 and for items of HCS_HU2 (in Hungary for the second phase) are presented in Table 5.

\section{Table 4 I HCS_SK2}

\begin{tabular}{lccc}
\multicolumn{1}{c}{ HEALTH CONSCIOUSNESS SCALE: H.C.S. } & $\begin{array}{c}\text { Mean } \\
\text { scores }\end{array}$ & St. dev. & $\begin{array}{c}\text { Cronbach } \\
\text { alpha }^{\star \star}\end{array}$ \\
\hline 1. I reflect about my health a lot. & 3.49 & 1.00 & 0.791 \\
2. I'm very self-conscious about my health. & 2.48 & 1.11 & 0.727 \\
3. I'm generally attentive to my inner feelings about my health. & 2.33 & 0.94 & 0.830 \\
4. I'm constantly examining my health. & 2.89 & 0.84 & 0.854 \\
5. I'm alert to changes in my health. & 3.40 & 1.13 & 0.735 \\
6. I'm usually aware of my health. & 2.96 & 1.13 & 0.744 \\
7. I'm aware of the state of my health as I go through the day. & 3.27 & 1.04 & 0.807 \\
8. I notice how I feel physically as I go through the day. & 4.30 & 0.46 & 0.826 \\
9. I'm very involved with my health. & 3.03 & 1.16 & 0.770 \\
\hline
\end{tabular}

Source: Own calculation.

Notes: * Based on Gould (1988).

${ }^{* *}$ Overall Alpha $=0.831$ 


\begin{tabular}{|c|c|c|c|}
\hline HEALTH CONSCIOUSNESS SCALE: H.C.S.* & $\begin{array}{l}\text { Mean } \\
\text { scores }\end{array}$ & St. dev. & $\begin{array}{l}\text { Cronbach } \\
\text { alpha }^{\star \star}\end{array}$ \\
\hline 1. I reflect about my health a lot. & 2.99 & 1.37 & 0.728 \\
\hline 2. I'm very self-conscious about my health. & 2.96 & 1.36 & 0.723 \\
\hline 3. I'm generally attentive to my inner feelings about my health. & 2.92 & 1.36 & 0.689 \\
\hline 4. I'm constantly examining my health. & 3.06 & 1.33 & 0.721 \\
\hline 5. I'm alert to changes in my health. & 2.77 & 1.50 & 0.674 \\
\hline 6. I'm usually aware of my health. & 2.90 & 1.32 & 0.687 \\
\hline 7. I'm aware of the state of my health as I go through the day. & 3.01 & 1.43 & 0.681 \\
\hline 8. I notice how I feel physically as I go through the day. & 3.00 & 1.50 & 0.667 \\
\hline 9. I'm very involved with my health. & 2.96 & 1.29 & 0.681 \\
\hline
\end{tabular}

Source: Own calculation.

Notes: * Based on Gould (1988).

${ }^{* *}$ Overall Alpha $=0.740$

As we can see in the case of Slovakia (second measurement), the total value of Cronbach's alpha value is 0.831 , which can be interpreted as a high value, and in the case of Hungary (second measurement), the total value of Cronbach's alpha value is 0.740 , which can be interpreted as a high value. (Tavakol \& Dennick, 2011) In the case of Hungary, it is not necessary to adjust the scale, but the second measurement suggests that in the conditions of Slovakia, it would be appropriate to exclude statement 4. - I'm constantly examining my health. From the point of view of the internal consistency of the scale, this statement reaches extreme values. However, this may be a fluctuation due to the time at which the survey was conducted, so we recommend that you keep the item in future surveys and then examine it further. The standard deviation of the mean represents the dispersion of the calculated arithmetic mean across the different samples selected from one main population. The standard deviation shows to what extent the individual measured values are around the mean value. The smaller the standard deviation, the closer the measured values are to the mean value. If the variance is smaller, it can be understood that the statement was rated similarly by all respondents. In the case of Slovakia (HCS_SK2), we see a low rate of standard deviation, which can be understood as a strong consistency of responses. In the case of Hungary (HCS_HU2), we can notice a higher rate of standard deviation, which can be understood as a higher diversity of respondents' answers.

Based on aims, we propose the following hypotheses $(H)$ and research questions (R.Q.):

RQ1a: What is the level of health consciousness during the remission of a pandemic (coronavirus) in Slovakia?

RQ1b: What is the level of health consciousness during the remission of a pandemic (coronavirus) in Hungary?

RQ2a: What is the level of health consciousness during the onset of the second wave of coronavirus in Slovakia?

RQ2b: What is the level of health consciousness during the onset of the second wave of coronavirus in Hungary?

RQ3a: What are the differences in the health consciousness of Slovaks during the remission of a pandemic and during the onset of the second wave of coronavirus? 
RQ3b: What are the differences in the health consciousness of Hungarians during the remission of a pandemic and during the onset of the second wave of coronavirus?

RQ4: What are the differences between Slovakia and Hungary in the context of health consciousness?

RQ5: What impact of health consciousness on compliance with and implementation of W.H.O. preventive recommendations against the spread of coronavirus. (Recommendations are based on W.H.O, 2020c.)

$\mathrm{H} 1$ : There is a relationship between health consciousness and monitoring of current information about coronavirus in our country.

$\mathrm{H} 2$ : There is a relationship between health consciousness and monitoring of the current situation regarding coronavirus in the world.

$\mathrm{H} 3$ : There is a relationship between the level of health consciousness and the willingness to wear a veil (mask).

$\mathrm{H} 4$ : There is a relationship between the level of health consciousness and the willingness to disinfect hands.

H5: There is a relationship between the level of health consciousness and keeping safe distances from people who cough and sneeze.

\section{Results and discussion}

The aim is fourfold: 1 . Measurement of the level of health consciousness during the remission of a pandemic (coronavirus) in Slovakia and Hungary, 2. Measurement of the level of health consciousness during the onset of the second wave of coronavirus, 3. Examining of differences between health consciousness during decline and re-emergence of coronavirus in Slovaks and Hungarians, 4. Examining the impact of health consciousness on compliance with and implementation of W.H.O. preventive recommendations against the spread of coronavirus. Based on this aim, we have developed hypotheses and research questions, the verification and answers of which we focus on in the next chapter of the article.

RQ1a: What is the level of health consciousness during the remission of a pandemic (coronavirus) in Slovakia?

The average measured value of H.C.S. in Slovakia was 20.95 points (st. dev. 4.479), which is below the average in scale (scale average $-27 ;\langle 9,45\rangle$ scale). The average calculation error is 0.229 points. The lowest measured rate of HCS_1 has reached 9 points, which is the smallest possible measurable value. The modus represents a value of 25 points and a median of 22. The total value measured - HCS_SK1 is considerably lower than average.

RQ1b: What is the level of health consciousness during the remission of a pandemic (coronavirus) in Hungary?

The mean of H.C.S. in Hungary was 31.34 points with st. dev. 6.808, which is over the average of scale (scale average - $27 ;<9,45>$ scale. The mean calculation error was 0.347 . Modus was 25 points and median 33 points. HCS_HU1 is above average. 
RQ2a: What is the level of health consciousness during the onset of the second wave of coronavirus in Slovakia?

The average measured value of H.C.S. in Slovakia was 28.16 points (st. dev. 4.525), which is roughly the average value of the scale (scale average $-27 ;\langle 9,45\rangle$ scale). The average calculation error is 0.231 points. The modus represents a value of 25 points and a median of 27. The total value measured - HCS_SK2 as an average.

RQ2b: What is the level of health consciousness during the onset of the second wave of coronavirus in Hungary?

The mean of H.C.S. in Hungary was 26.57 points with st. dev. 7.157, which is over the average of scale (scale average - $27 ;<9,45>$ scale. The mean calculation error was 0.365 . Modus was 30 points and median 28 points. The Total HCS_HU2 value is above average.

RQ3a: What are the differences in the health consciousness of Slovaks during the remission of a pandemic and during the onset of the second wave of coronavirus?

At the time of the release and decline in the number of infected, we measured a health consciousness level of approximately $33.20 \%$. However, at a time of a sharp increase in those infected, this rate rose to $53.23 \%$. From the above, it can be stated a significant difference, which represents a $60 \%$ increase in health consciousness.

RQ3b: What are the differences in the health consciousness of Hungarians during the remission of a pandemic and during the onset of the second wave of coronavirus?

At the time of the release, we measured a health consciousness rate of around $62 \%$ in Hungary, which can be interpreted as a high value. At the time of the increase in the number of infected, we measured a $48.79 \%$ level of health consciousness. It can therefore be stated that the level of health consciousness has decreased by about $21 \%$.

RQ4: What are the differences between Slovakia and Hungary in the context of health consciousness?

In the first period examined, Hungary achieved a higher health consciousness (index 1.68 against Slovakia), but in the second measurement, Slovakia achieved a higher health consciousness (index 1.09 compared to Hungary). It can be stated that there were significant differences in the first measurement, but in the second measurement, the difference represents only about $9 \%$.

RQ5: What impact of health consciousness on compliance with and implementation of W.H.O. preventive recommendations against the spread of coronavirus.

For a comprehensive answer to the research question, we divide it into five hypotheses. It is necessary to realize that although we have formulated five hypotheses, it is necessary to verify them in two phases of the survey and in two sections (Slovakia, Hungary). We verified the hypotheses on the basis of the ANOVA test and regression analysis. The reason why we chose regression analysis is that it gives us a clear picture not only of the existence but also of the direction and intensity of the investigated relationships. The basic values obtained from the ANOVA test and regression analysis were recorded in Table 6. 
Table 6 I Hypothesis results

\begin{tabular}{lcccc}
\hline & P value $^{*}$ & Multiple R & Standard Error & Regression model \\
\hline H1 SK1 & 0.000 & 0.727 & 1.682 & $y=4.125 x+11.06$ \\
H2 SK1 & 0.000 & 0.708 & 2.640 & $y=2.686 x+13.24$ \\
H3 SK1 & 0.487 & - & - & - \\
H4 SK1 & 0.000 & 0.789 & 2.754 & $y=5.074 x+10.72$ \\
H5 SK1 & 0.000 & 0.719 & 3.119 & $y=1.809 x+17.06$ \\
\hline H1 SK2 & 0.000 & 0.834 & 2.498 & $y=3.694 x+19.52$ \\
H2 SK2 & 0.000 & 0.729 & 1.671 & $y=3.175 x+19.22$ \\
H3 SK2 & 0.000 & 0.499 & 3.927 & $y=2.122 x+23.78$ \\
H4 SK2 & 0.000 & 0.775 & 2.865 & $y=4.457 x+19.19$ \\
H5 SK2 & 0.000 & 0.705 & 0.497 & $y=2.586 x+20.43$ \\
\hline H1 HU1 & 0.000 & 0.893 & 3.071 & $y=4.902 x+13.90$ \\
H2 HU1 & 0.000 & 0.894 & 3.059 & $y=4.789 x+14.65$ \\
H3 HU1 & 0.538 & - & - & \\
H4 HU1 & 0.000 & 0.789 & 4.186 & $y=6.867 x+17.33$ \\
H5 HU1 & 0.000 & 0.853 & 3.558 & $y=8.515 x+17.34$ \\
\hline H1 HU2 & 0.000 & 0.742 & 2.406 & $y=5.099 x+11.82$ \\
H2 HU2 & 0.000 & 0.710 & 5.048 & $y=3.575 x+17.76$ \\
H3 HU2 & 0.000 & 0.224 & 6.985 & $y=0.912 x+23.11$ \\
H4 HU2 & 0.000 & 0.841 & 3.882 & $y=7.584 x+11.45$ \\
H5 HU2 & 0.000 & 0.790 & 3.262 & $y=5.714 x+13.18$ \\
\hline
\end{tabular}

Source: own calculations.

Note: * alpha $=0.05$

The first step in examining the hypotheses was to verify them based on the ANOVA test. As we can see (Table 4), except for hypothesis 3, which was verified in the conditions of Slovakia in the first phase (H3 SK1) and in the conditions of Hungary in the first phase (H3 HU1), we managed to confirm the hypotheses at the level of reliability alpha $=0.05$. As we rejected the hypotheses in $\mathrm{H} 3 \mathrm{SK} 1$ and $\mathrm{H} 3 \mathrm{HU} 1$, no further investigation by regression analysis was necessary. In other cases, we examined the intensity and strength of relationships in more detail based on regression and correlation analysis. In our case, we determined the examined variables for $x$ and for H.C.S., we determined the value of H.C.S. (relevant to the country and phase).

$\mathrm{H} 1$ : There is a relationship between health consciousness and monitoring of current information about coronavirus in our country.

The hypothesis can be confirmed both in the conditions of Slovakia and in the conditions of Hungary. Based on the results of the regression analysis, it is possible to state a higher degree of interdependence between health consciousness and monitoring of current information about coronavirus in our country in Slovakia and Hungary (in both phases). In all cases, this is a positive relationship on the basis of which it can be stated that consumers who are interested in the development of coronavirus in their country also achieve a higher level of health consciousness and vice versa.

$\mathrm{H} 2$ : There is a relationship between health consciousness and monitoring of the current situation regarding coronavirus in the world. 
The hypothesis can be confirmed in the conditions of Slovakia and in the conditions of Hungary. Based on the results of the regression analysis, it is possible to state a higher degree of interdependence between health consciousness and monitoring of the current situation regarding coronavirus in the world in Slovakia and Hungary (in both phases). In all cases, this is a positive relationship on the basis of which it can be stated that consumers who are interested in the development of coronavirus in the world also achieve a higher level of health consciousness and vice versa.

$\mathrm{H} 3$ : There is a relationship between the level of health consciousness and the willingness to wear a veil (mask).

The hypothesis can only be confirmed in the second phase of the study (H3 SK2 and H3 HU2). However, based on the results of the regression analysis, it can be stated that this is a small dependence. Thus, it can be stated that the willingness to wear a veil (mask) has no significant relationship with the degree of health consciousness.

$\mathrm{H}$ 4: There is a relationship between the level of health consciousness and the willingness to disinfect hands.

We can confirm the hypothesis in all examined phases in both studied countries. Based on the regression analysis, a strong positive relationship can be stated. Based on the above, it can be stated that consumers who often disinfect their hands also achieve a higher level of health consciousness.

$\mathrm{H} 5$ : There is a relationship between the level of health consciousness and keeping safe distances from people who cough and sneeze.

The hypothesis can be confirmed in the conditions of Slovakia and in the conditions of Hungary. Based on the results of the regression analysis, it is possible to state a higher degree of interdependence between health consciousness and keeping safe distances from people who cough and sneeze in Slovakia and Hungary (in both phases). In all cases, this is a positive relationship on the basis of which it can be stated that consumers who are keeping safe distances from people who cough and sneeze also achieve a higher level of health consciousness and vice versa.

Our study deals with the issue of health consciousness. The study provides an overview of two countries, namely Hungary and Slovakia. The research took place in two phases, the first being careful after the first wave during the release period and the second phase of the measurement taking place during the oncoming second wave. According to the Čvirik study (2020), there is a significant link between health consciousness in connection with the spread of coronavirus. In the case of Slovakia, it can be stated that during the onset of the second wave, there was an increase in the level of health consciousness. This is a logical analogy, with consumers taking more care of their health with increased concern for their health. In the case of the Hungarians, there was a decrease in the second phase of the investigation. There may be several reasons. We believe that the main reason why the level of health consciousness has fallen is that Hungary was not yet in the second wave of the pandemic. As many records show, there was only a slight increase in infections in Hungary, while in Slovakia, the rate of active cases increased rapidly. The results of the study also showed a significant relationship between the level of health consciousness and the cognitive component of consumers, whether it was the acquisition of knowledge about the 
development of coronavirus in the home country or worldwide. This result can be understood in the sense that respondents who know the better situation in a given country/world are more cautious and more interested in their health. Based on the findings, it is not possible to confirm that respondents with a higher level of health consciousness are more willing to wear veils (face masks), which we consider a surprising finding. Although many experts claim that veils help in the fight against coronavirus, there are also many opponents. Health consciousness also affects the willingness to disinfect your hands. It can be stated that respondents with higher health consciousness are more willing not to disinfect their hands. This is a logical step in coronavirus prevention, thus promoting health consciousness. We also consider it important to find out that respondents who achieve higher health consciousness also keep their distance from people who have a visible manifestation of the disease (cough, sneezing). Again, it is possible to understand this point in terms of prevention, and therefore it is logical that respondents who maintain a given distance also have a higher overall health consciousness.

\section{Conclusion}

The study had a goal to examine health consciousness and the recommendations of W.H.O. against the spread of coronavirus in Slovakia and Hungary during the decline and reemergence of coronavirus.

Based on the results of the primary survey, it can be stated that health consciousness in Slovakia has increased due to the deterioration of the coronavirus situation. In the case of Hungary, there has been a slight decline, but this may be due to the fact that Hungary was not yet exactly at the time of the second wave of the pandemic.

It can be stated that at the time of the release of the measures as well as at the time of the onset of the second wave, the following statements apply:

- consumers who monitor the coronavirus situation in their country achieve a higher level of health consciousness,

- $\quad$ consumers who monitor the situation with the virus in the world are achieving a higher level of health consciousness,

- $\quad$ consumers who are more willing to disinfect their hands have a higher level of health consciousness,

- $\quad$ consumers who keep their distance from others who show signs of disease achieve a higher level of health consciousness.

Based on the above, it can be concluded that it is necessary to achieve a higher level of health consciousness for consumers. It is also necessary to inform consumers correctly about the situation in order to be able to react correctly, which naturally changes their healthconscious behaviour. Health consciousness and adherence to basic recommendations and hygiene are an important elements of prevention in times without a vaccine. 


\section{References}

Adler, S. E. (2020). Why Coronaviruses Hit Older Adults Hardest. Retrieved July 11, 2020. https://www.aarp.org/health/conditions-treatments/info-2020/coronavirus-severe-seniors.html.

Čvirik, M. (2020). Health Conscious Consumer Behaviour: The Impact of a Pandemic on the Case of Slovakia. Central European Business Review, 9(4), 45-58. https://doi.org/10.18267/j.cebr.249.

ECDC (2020). COVID-19 pandemic. Retrieved July 12, 2020. https://www.ecdc.europa.eu/en/covid-19pandemic.

Gould, S. J. (1988). Consumer Attitudes Toward Health and Health Care: A Differential Perspective. Journal of Consumer Affairs, 22(1), 96-118. https://doi.org/10.1111/j.1745-6606.1988.tb00215.x.

Gould, S. J. (1990). Health consciousness and health behavior: The application of a new health consciousness scale. American Journal of Preventive Medicine, 6(4), 228-237. https://doi.org/10.1016/S0749-3797(18)31009-2.

Jayanti, R. K., \& Burns, A. C. (1998). The antecedents of preventive health care behavior: an empirical study. Journal of the Academy of Marketing Science, 26(1), 6-15. https://doi.org/10.1177/0092070398261002.

Kritas, S. K., Ronconi, G., Caraffa, A., Gallenga, C.E., Ross, R., \& Conti, P. (2020). Mast cells contribute to coronavirus-induced inflammation: new anti-inflammatory strategy. Journal of Biological Regulators \& Homeostatic Agents, 34(1), 9-14.

Lockie, S., Lyons, K., Lawrence, G., \& Mummery, K. (2002). Eating 'green': motivations behind organic food consumption in Australia. Sociologia Ruralis, 42(1), 23-40. https://doi.org/10.1111/14679523.00200 .

Lu, R., Zhao, X., Li, J., Niu, P., Yang, B., Wu, H., Wang, W., Song, H., Huang, B., Zhu, N., Bi, Y., Ma, X., Zhan, F., Wang, L., Hu, T., Zhou, H., Hu, Z., Zhou, W., Zhao, L., Chen, J., Meng, Y., Wang, J., Lin, Y., Yuan, J., Xie, Z., Ma, J., Liu, W. J., Wang, D., Xu, W., Holmes, E. C., Gao, G.F., Wu, G., Chen, W., Shi, W., \& Tan, W. (2020). Genomic characterization and epidemiology of 2019 novel coronavirus: implications for virus origins and receptor binding. Lancet pii: S01406736(20)30251-8. https://doi.org/10.1016/S0140-6736(20)30251-8.

Michaelidou, N., \& Hassan, L. M. (2008). The role of health consciousness, food safety concern and ethical identity on attitudes and intentions towards organic food. International Journal of Consumer Studies, 32(2), 163-170. https://doi.org/10.1111/j.1470-6431.2007.00619.x.

N.Y.C. Health (2020). August 02, 2020. https://www1.nyc.gov/assets/doh/downloads/pdf/imm/covid-19daily-data-summary-deaths-05132020-1.pdf.

Population city. (2020). Mad’arsko. August 02, 2020. http://obyvatelstvo.population.city/madarsko/\#1.

SOSR (2020). Statistical office of the Slovak republic. Retrieved April 09, 2020, from <http://datacube.statistics.sk/\#!/view/sk/SODB/hc1okr/Obyvate\%C4\%BEstvo\%20pod\%C4\%BE a\%20miesta\%20s\%C4\%8D\%C3\%ADtania,\%20pohl.,\%20postav.\%20v\%20dom\%C3\%A1c.,\%2 Orodinn.\%20stavu,\%20ekonom.aktivity,\%20miesta\%20narod.,\%20\%C5\%A1t\%C3\%A1t.\%20pr \%C3\%ADslu\%C5\%A1.\%20a\%20veku\%20-\%20HC1>.

Stokes, J., Noren, J., \& Shindell, S. (1982). Definition of terms and concepts applicable to clinical preventive medicine. Journal of Community Health, 8(1), 33-41. https://doi.org/10.1007/BF01324395.

Tavakol, M., \& Dennick, R. (2011). Making sense of Cronbach's alpha. International Journal of Medical Education, 2(1), 53-55. https://doi.org/10.5116/ijme.4dfb.8dfd 
W.H.O. (2020a). Constitution. Retrieved April 09, 2020. https://www.who.int/about/who-weare/constitution.

W.H.O. (2020b). August 13, 2020, from https://www.euro.who.int/en/health-topics/health-policy/health2020-the-european-policy-for-health-and-well-being.

W.H.O. (2020c). Advice for public. August 13, 2020. https://www.who.int/emergencies/diseases/novelcoronavirus-2019/advice-for-public.

Worldometer. (2020a). Slovakia. August 10, 2020.

https://www.worldometers.info/coronavirus/country/slovakia/.

Worldometer. (2020b). Hungary. August 10, 2020.

https://www.worldometers.info/coronavirus/country/hungary/.

Worldometer. (2020c). Population by country. August 11, 2020. https://www.worldometers.info/worldpopulation/population-by-country/.

Wu, Z., \& McGoogan, J. M. (2020). Characteristics of and important lessons from the coronavirus disease 2019 (COVID-19) outbreak in China: summary of a report of 72314 cases from the Chinese Centre for Disease Control and Prevention. JAMA, 323(13), 1239-1242. doi:10.1001/jama.2020.2648.

The research article passed the review process. | Received: October 3, 2020; Revised: March 3, 2021; Accepted: April 23, 2021; Pre-published online: April 24, 2021; Published in the regular issue: September 20, 2021. 